\title{
Dwelling together: A visual approach to an ecovillage's sense of place
}

Jonathan Taggart*

Royal Roads University, Canada

\begin{abstract}
This paper and photographic essay present an empirical characterization and theoretical treatment of an ecovillage. Informed by the principles of sensory ethnography, my representation aims to describe and interpret an ecovillage as a place defined by practice. The author approaches this characterization from a dwelling perspective, emphasizing the performances of ecovillagers in a series of photographic and textual vignettes. The author concludes that an ecovillage may be considered, in part, as a place where familiar tasks are undertaken in unfamiliar ways in a vast and varied physical and social landscape.
\end{abstract}




\section{Introduction}

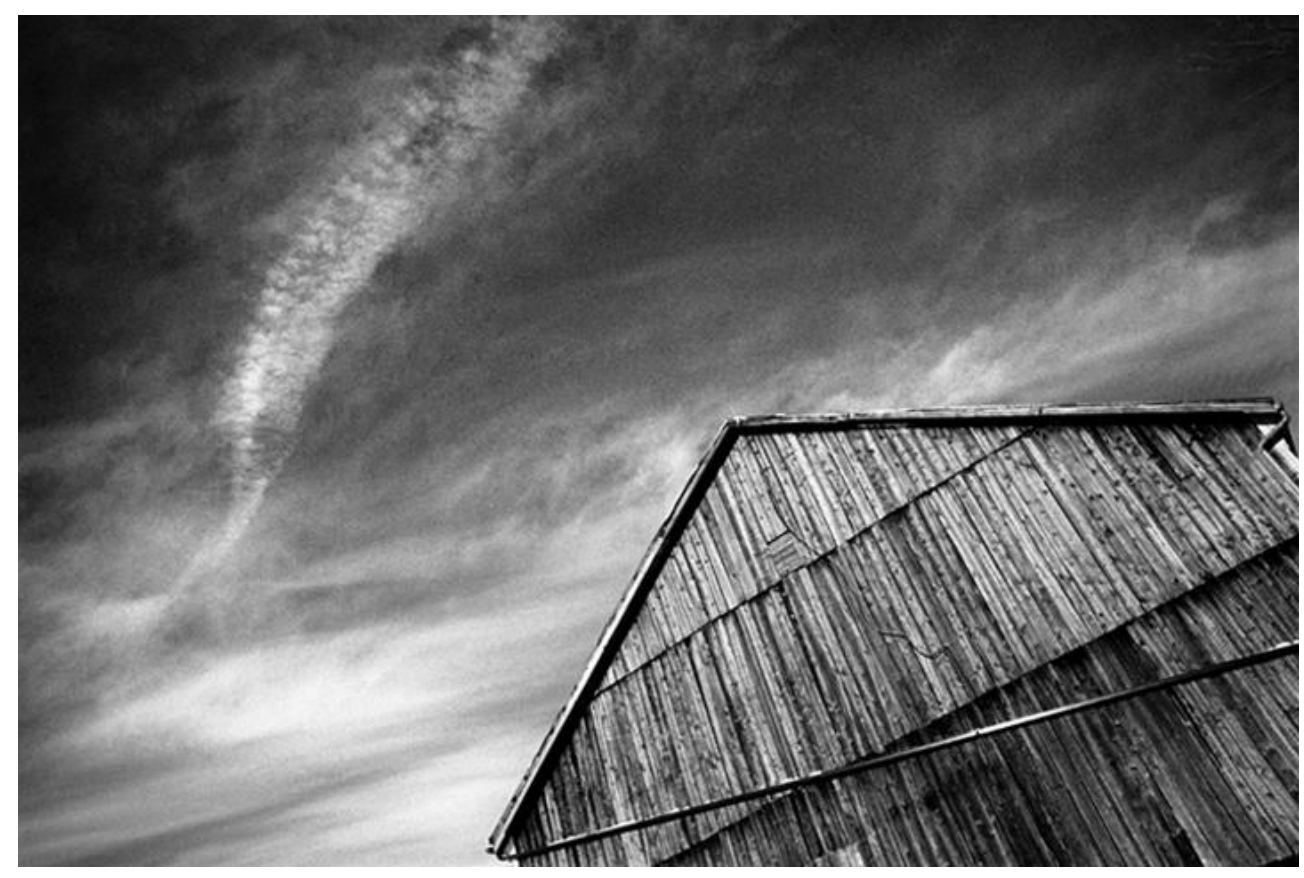

The Old Barn

The visual and textual data presented here are the result of an 18-month involvement with a 30-member sustainable agricultural community in Dufferin County, Ontario. The community (whose name, as well as those of its inhabitants, have here been anonymized in the interests of privacy) is a self-described ecovillage- "a sustainable human settlement which is in harmony with all aspects of life, including the cultural, ecological and spiritual dimensions" (Gaia Trust) — founded in response to a perceived loss of genuine community, the increased urbanization of rural areas, and the growing impoverishment of farmland; Its diverse membership is comprised of educators, professionals, students, volunteers and farmers living in a 15,000 square-foot co-operative residence (here named 'Big Building') and a turn-of-the-century farmhouse. The community purports to offer a solution to the frustrations faced by environmentally conscious urbanites: in contrast to the tarpaper shack and haphazard "free love" stereotypes associated with communes of the 1960s (for a comprehensive overview of the commune movement see Miller, 1999), the ecovillage under study is highly organized and surprisingly modern. The farm's main residence set a zoning precedent with a green design that prioritizes personal space while preserving communal eating and recreation areas, and the consensus leadership model that helped administer the 
group's farm purchase now ensures a level of social and financial accountability among community members. The way of life the community supports aims to blend traditional family values with modern ecological practices, and the result is what one member describes as being more like a "condo on a farm" than a contemporary commune.

Ecovillages have been alternately touted as hopeful lived experiments (Kilián, 2009, pp. 365-371) and dismissed as inconsequential, having neither the membership nor the political inroads to affect significant societal change beyond their walls (Fotopoulos, 2000, pp. 287-308). They have been examined as rejections of an oppressive Western worldview and an articulation of human-ecosystem interdependence (Kasper, 2008, pp. 12-24), and as a parallel pastorialist compliment to urban social movements (Conn, 2010, pp. 831-848). Similarly, Lietaert (2010) asserts that ecovillage "cohousing is a constructive step towards degrowth at the family and neighbourhood level" (p. 580), positioning ecovillages as a necessary alternative to unsustainable economic growth fueled by "hyper-individualism" (p. 580) and material cultural. And Ergas (2010) draws on her own participant observation and interviews to assess the collective (and often conflicted) identity of an urban ecovillage as a social movement vis-a-vis proximate political structures, concluding that "despite hardship, these actors have found ways to maintain their vision and share it with others" (p. 50). While each of these authors plays an important role in positioning ecovillages, along with their inherent contributions, conflicts and conundrums, in sociopolitical space and time, it is not the author's aim to situate the particular ecovillage under study historically, politically, socially, or environmentally. The study's goal is to situate the ecovillage, in words and images, as a place defined by its attendant rhythms, juxtapositions, and lines.

\section{A Non-representational Perspective}

In response to Gibson's (1979) ecological approach to perception, Ingold (2008) has argued that "life is lived in a zone in which earthly substances and aerial media are brought together in the constitution of beings which, in their activity, participate in weaving the textures of the land" (p. 1796), and that through this performative weaving places as we know them become incorporated. This perspective, along with its accompanying ideas of movement, can be situated under the umbrella of nonrepresentational theory, which has as its central tenet the proposition that realities are made up of performances and practices (Lorimer, 2005, pp. 83-94). Just as Vanini and Taggart (2012) have argued that an island's sense of place is defined by the way islanders move, here the author proposes that an ecovillage's sense of place can too be defined by the way ecovillagers move, through a space where seasonal and societal forces act and 
interact upon an interface of social substrate and soil. These movements are described as being heavily varied, rhythmically diverse in both their physicality and sociality, and are often at the mercy of those fluxes of medium known as weather (Ingold, 2005, pp. 97-104). In doing so, the author uses folk categories pertaining to an ecovillage's specific geography to situate descriptions of embodied phenomena, aiming to move beyond the trivialities of task and technique (which are left out of this analysis in any holistic sense for considerations of space) to examine the shared performative experiences that attempt to define and identify ecovillagers. These specific geographies can be seen as stages for a series of vignettes - sensual descriptions of activities and interactionsaccompanied by a collection of black and white photographs.

\section{Picking tomatoes: An immersive approach to photo-ethnography}

Ethnographers have written extensively about the need to negotiate identities when working with(in) communities (Crang \& Cook, 2007, pp. 42-43; Cassell, 1988). Cassell particularly suggests that, of the numerous identities available to researchers, "the most appropriate one can be stressed" (1988, p. 97). The research presented here was undertaken during the production of my undergraduate photography thesis, completed in 2008, and over the course of those 18 months the author lived in this particular ecovillage in week-long episodes, working half-time on the farm to earn my room and board. The author's interest in the community stemmed from a burgeoning interest in sustainability, rurality, and small-scale agriculture, and as a result of this blended academic and personal approach had many identities from which to choose. Under the umbrella identities of researcher and student were the rotating identities of volunteer, paying guest, farmhand, photographer, kitchen aide and so on, and this dynamic presence allowed for fieldwork that was highly immersive and experiential: in addition to a handful of semi-structured interviews, in compiling this textual data the author drew largely upon participant observation (Crang \& Cook, 2007, pp. 37-59) that includes preparing communal meals, feeding chickens, picking tomatoes, cleaning barns, carting bricks, shoveling snow, and painting floors, to name but a few activities and chores. 


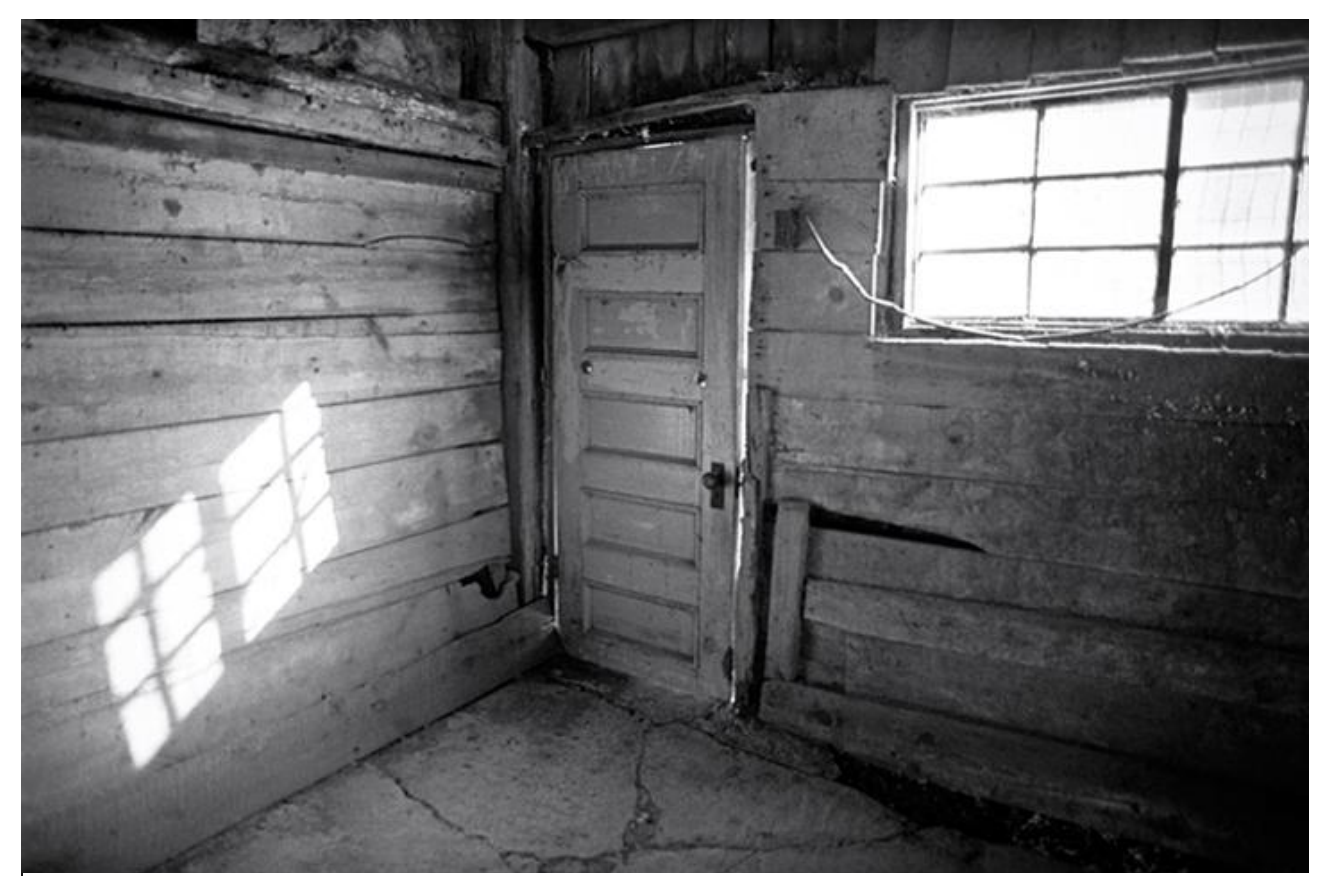

An interior view of a storage room in the barn, seen after the author finished clearing a stack of old bricks from beneath the window.

Crang and Cook (2007) assert that "to be a 'participant' in a culture implies an immersion of the researcher's self into the everyday rhythms and routines of the community" (original emphasis, p. 37), and as a result of this hands-on engagement. Involving goals and tasks shared by researcher and subject alike, the vignettes presented here also draw significantly on principles of reflexive ethnography (Ellis, 2004, pp. 1-427). Interviews and reflections have been data analyzed following the procedures of post-phenomenological research (Moustakis, 1994, p. 121): horizontalizing the data, clustering units of meaning into common themes, developing descriptions of experiences and practices based on these clusters, and integrating descriptions into meanings, both experiential and theoretical. Photographs taken by the author are presented based on their adherence to, and articulation of, the meanings emerging from interviews and reflections, as well as on their aesthetic merit as determined by the author, a trained professional photojournalist. Additionally, the images presented here are intended not simply, as Sontag (1973) has reduced it, "to illustrate the analysis contained in an article" (p. 22), but to aid in thick description in hopes of conveying a nearer totality of experience (Pink, 2001, pp. 50-76). The accompanying photographs function not just as mnemonic devices for later analysis, but served in-situ as a means of understanding, as "to take a photograph is to participate in another person's . . . mortality, vulnerability, mutability” (Sontag, 1973, p. 15), and, I would add, sustainability. 


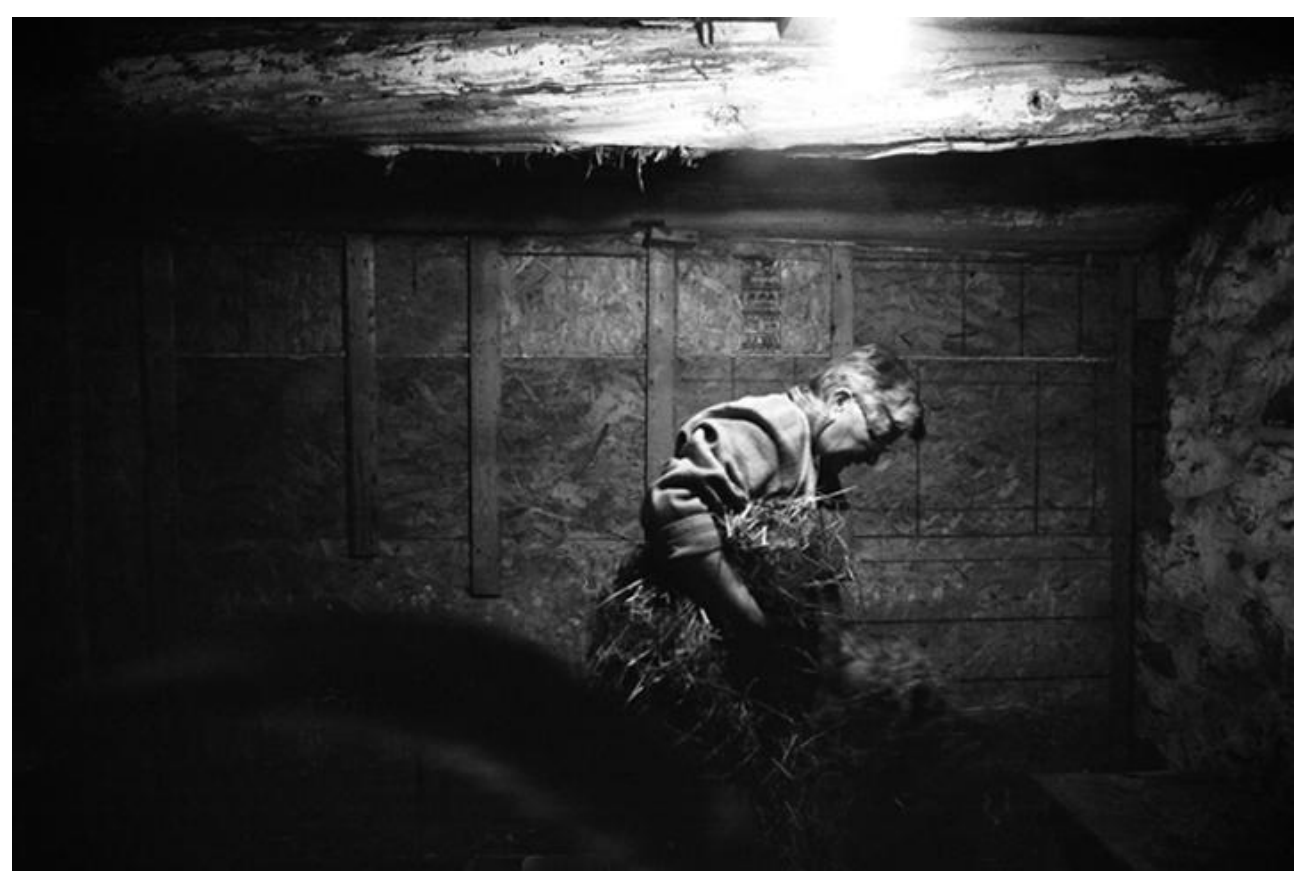

Doris working in the chicken coop while the author helps collects eggs.

\section{In the Car}

Driving the dusty lanes to the farm in the mid-morning, Doris, my host and a founding member of the ecovillage, describes and explains the events of the past few months. Like the washing line behind the house, the line between news and gossip is pulled taught in such a close-knit community, and the retired teacher's stories cross back and forth with the wind. Gerhardt, a male community member, had fallen for one of the farm's volunteers at the beginning of the season, and his behavior had become increasingly erratic and threatening as he was refused again and again. The hot, dry July was brought to a head with the stabbing of a farmhouse table; when the community confronted Gerhardt about his actions, members were torn between the hard-working, forty-year-old Ontario gypsy and the young, transient volunteer whose placement was nearly up. Many community members sided with Gerhardt, but he was asked to put some distance between himself and the intern. 


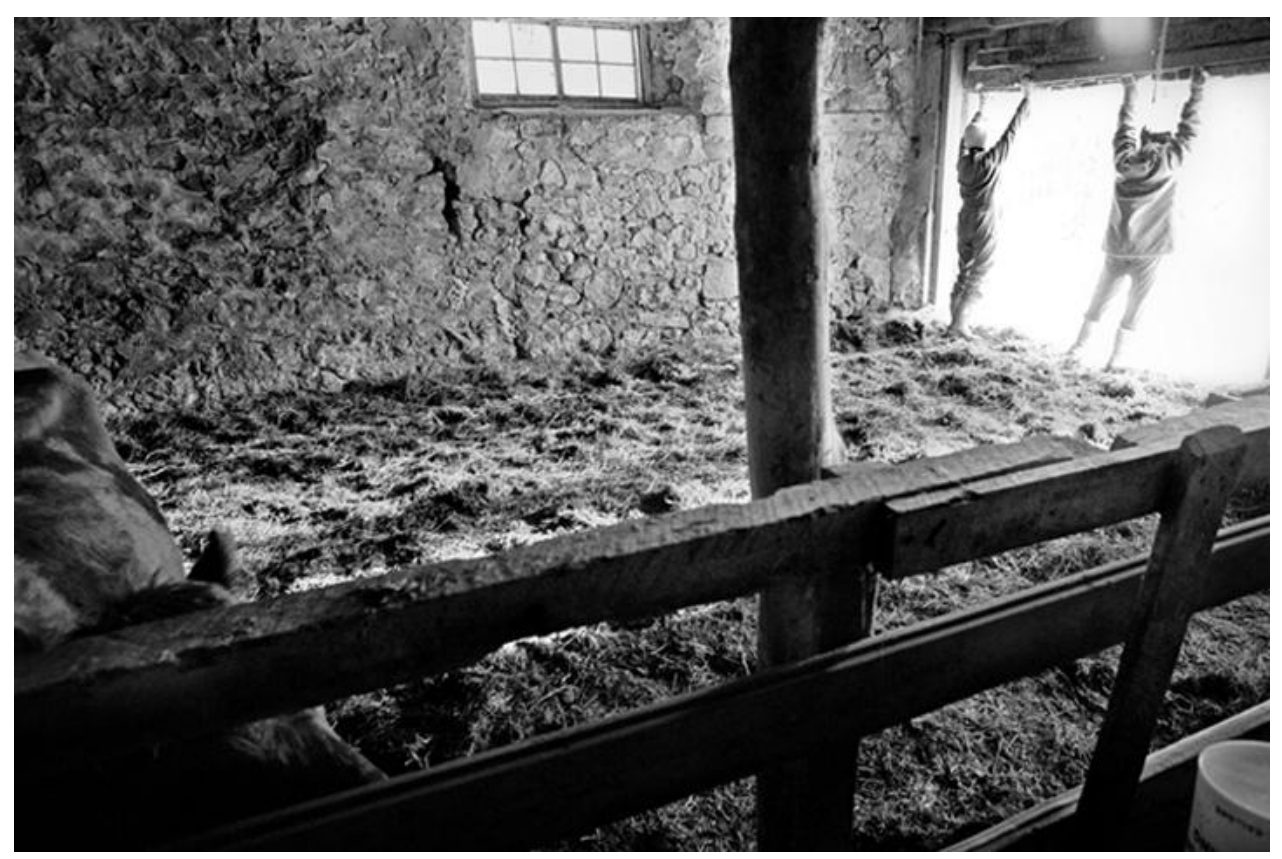

Community members open the door to the barn in preparation for a morning of milking cow.

Gerhardt is working in the barn's workshop one afternoon, shirtless and hunched over some pieces of farmhouse floorboard that are being stripped and resurfaced. The event is far from our topics of conversation but still he speaks very little, apparently indifferent to me and the few chickens pecking at the sawdust near the door. "Cities weren't made for people, they were made for cars," is his reply when asked if he had lived in the nearby city before moving to the ecovillage. "I never lived in the city." And with that curt dismissal, I slip sheepishly away through the sawdust and the chickens.

\section{In the Field}

James is a high school teacher on what he calls "indefinite farming leave." Hunched over a laundry basket with cracked and splayed sides that suggest a previous crop far bigger than the one this drought has brought, he explains the trick to picking tomatoes in a field with more varieties than I knew existed. 


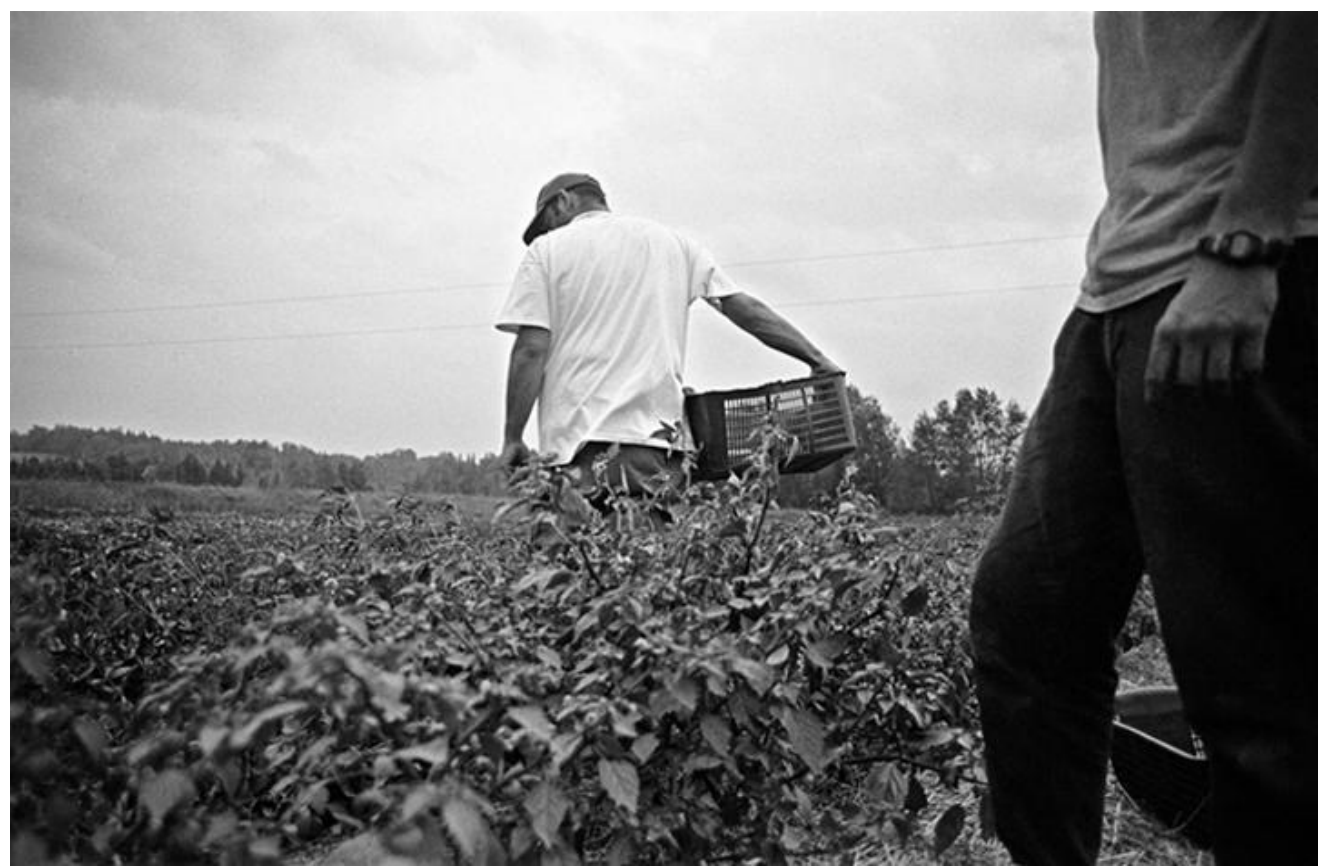

James and Emery, the head farmer, pick tomatoes in one of the community's fields.

Making our way slowly down the rows of plants, we face each other, offset by a few vines, backs (mine, at least) beginning to ache with the bending. The vines scratch our wrists, releasing the sweet and sour aromas of fruit and soil as we reach deep into the low tangles and carefully stack small ones upon the larger in our baskets. No supermarket, with its waxy, imported produce, would admit that customers could eat tomatoes as non-conforming as the ones being picked. "The small ones actually fetch a higher price at the farmers markets; people love them. The yellow ones are pretty popular too," James says as he lifts a large beefsteak, its underside blackened and blistered, into a separate pail. "Rotten tomato stew," he says by way of explanation. The crops have not seen a rain shower in eight weeks, and nothing is wasted. 


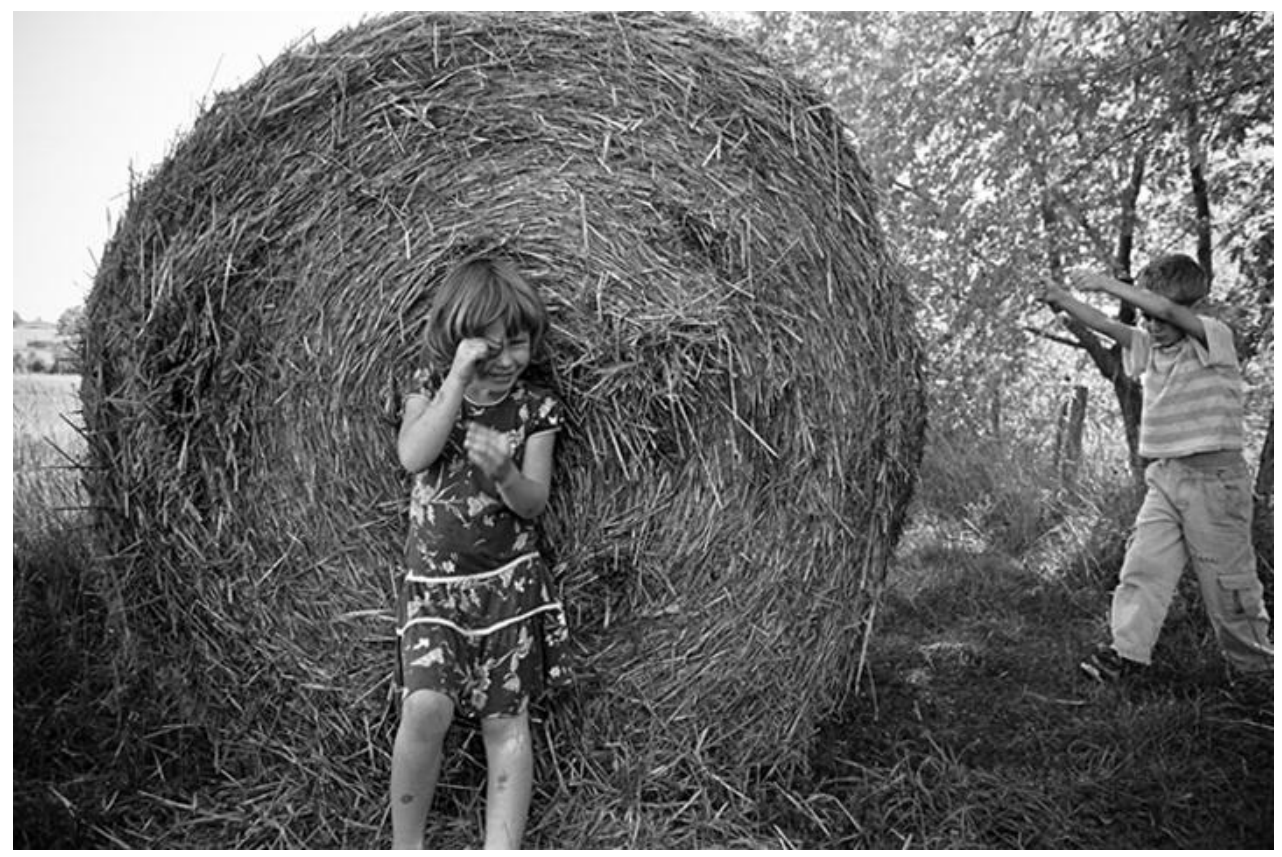

Alexa and Erik play around a hay bale near one of the community's fields.

The afternoon has been cloudy and warm, and as we reach the end of a row a sudden monsoon is unleashed upon us, dropping the dust in the field and making the leaves dance as if an electric current was running through their roots. It stops as suddenly as it started, a few minutes after it began. "Is that all the rain we're going to get?" James shouts at the sky.

The wind has picked up, and on the way back to the Big Building, Emery is found half-buried in the poly-tarp wall of a greenhouse, trying to re-attach the ripped material to a set of weighted wooden spreaders along the ground. The beginnings of a storm whips it about like a torn sail as we kneel on it together, frantically working nails into rotten wood and trying to keep the greenhouse's seedlings from being strewn about.

\section{In the Kitchen}

Henrietta, a visitor from Europe who is staying on the farm with her family, is making Dutch pancakes for tomorrow's work bee, the monthly event that invites in neighbours from the surrounding towns and countryside for the opportunity to get their hands dirty on the farm. This batch is being made with the buttermilk Emery brought down to the Big Building this morning, and they are sticking slightly to the 
glass frying pan. As the viscous disks collect pockmarks and congeal, she whisks raw milk in a pot on the stove and spoons it into our coffees.

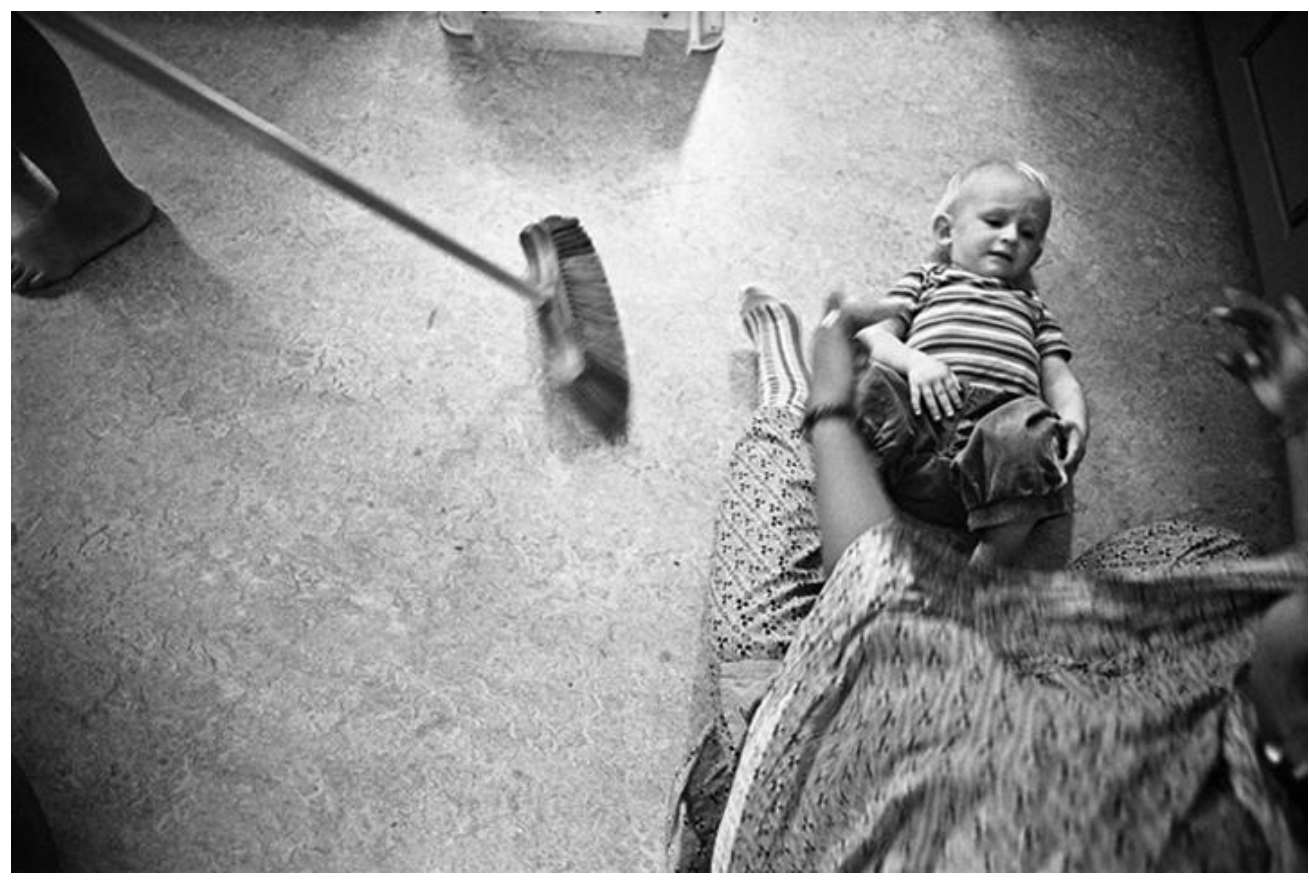

A seasonal volunteer plays with Mikey on the floor of the communal kitchen in the Big Building while his mother sweeps.

Emery walks into the kitchen with more milk from the farmhouse. After asking if he needs help with anything outside, he replies, "I don't think so," through teeth as erratically spaced as the young trees in the windbreak up the lane, "I'm going to take a nap and then go see a man about some cheese."

\section{In the Pond}

Kaye, 18, does a front flip off the swimming raft in the late afternoon, after the work bee is over and the volunteers have gone home. She spent the day working with Doris and the children, putting deer guards around the bases of the saplings that will one day serve as a windbreak against the western wind. A whiff of salt and soil is captured before the water engulfs her body. Her coarse black hair-the same as her mother's - sticks to her back as she climbs alongside her younger siblings into the vbottomed canoe her older brother made years ago, and she takes Alexa for a paddle around the pond as Erik swims beside them. 


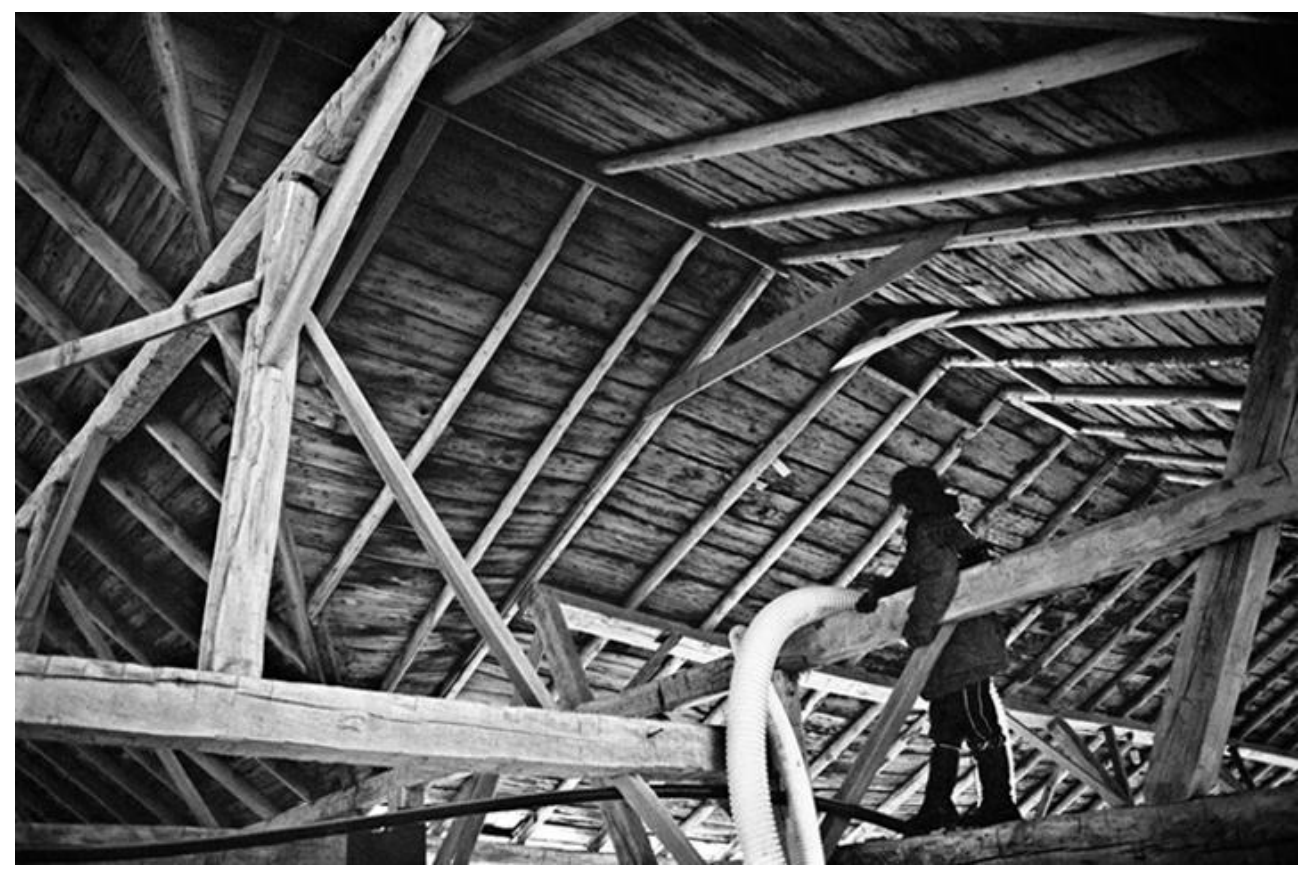

Kaye helps store extra building supplies in the rafters of the old barn during a community clean-up day.

\section{In the Honey Shed}

Nicolas' centrifuge lives in a dark corner of the maintenance room, between the furnace and a pile of Wellington boots, where he spins the honey from the combs he collects from the hives on the eastern edge of the pond. He has been thinking of leaving the community: his wife's allergies have gotten worse and she is finding it very difficult to live on the farm. At the moment they are in transition, living in the city and coming up to the farm on weekends to tend to the honey. As he loads each frame of honeycomb into the centrifuge he explains the concept of 'bee space', as proposed by Reverand L. L. Langstroth, he says, in 1853. The theory dictates the preferable distance between the frames in a hive to maximize productivity, a gap between a quarter and three-eighths of an inch. Spaces any smaller restrict the bees' access to parts of the comb; spaces any larger are bridged with wax, creating impasses that clog the hive.

There is a pile of Nicolas' belongings in the barn. Digging potatoes with Marianne, a long-standing member, in the afternoon, I ask her about Nicolas and his plans to leave. "He said his things will be gone by October 1 ${ }^{\text {st }}$," she says. "I think he just can't handle being around so many people all the time." 


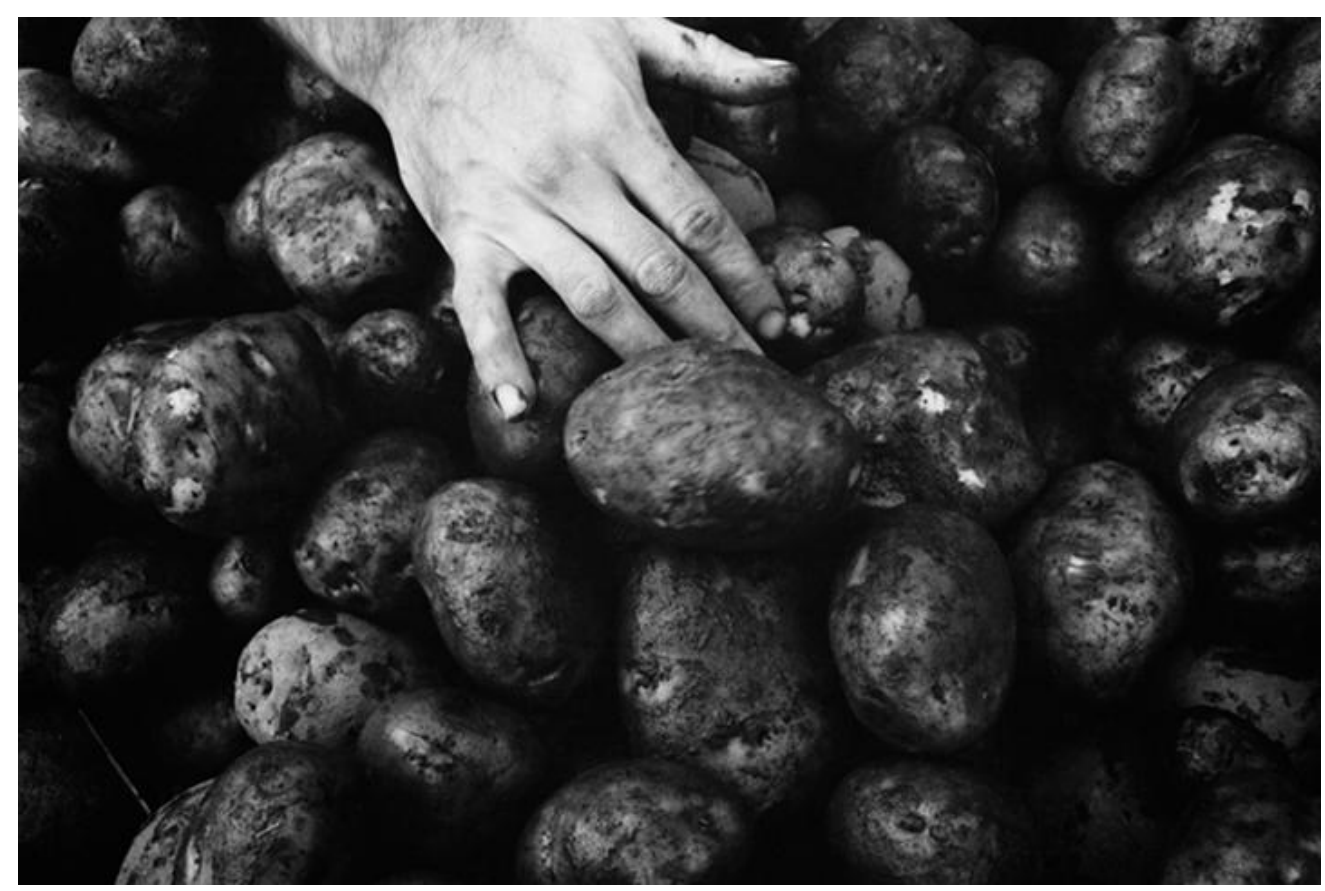

A seasonal volunteer sorts blighted potatoes after heavy rains.

In the kitchen that evening, Henrietta prepares dinner while Magda bottles honey at a low table. Henrietta talks about her brother Rex, a successful news photographer in Europe, and Magda talks about the small gallery in the city where she and Nicolas work-a gallery specializing in objective art. She says I should come visit sometime, saying that they also show some photography, prompting the argument from Henrietta and myself that no photography is objective: the act of framing a picture and releasing the shutter is selective and subjective, privileging a single moment and certain elements within a scene over all others. "And often it's what's not in a picture that is important," surmises Henrietta, using as a hypothetical example a photograph of shadows on the ground from a washing line. The image reminds me of the dark shapes of Nicolas' things under blankets in the barn, and of Gerhardt's knife wounds hidden beneath the honey jars on the table. 


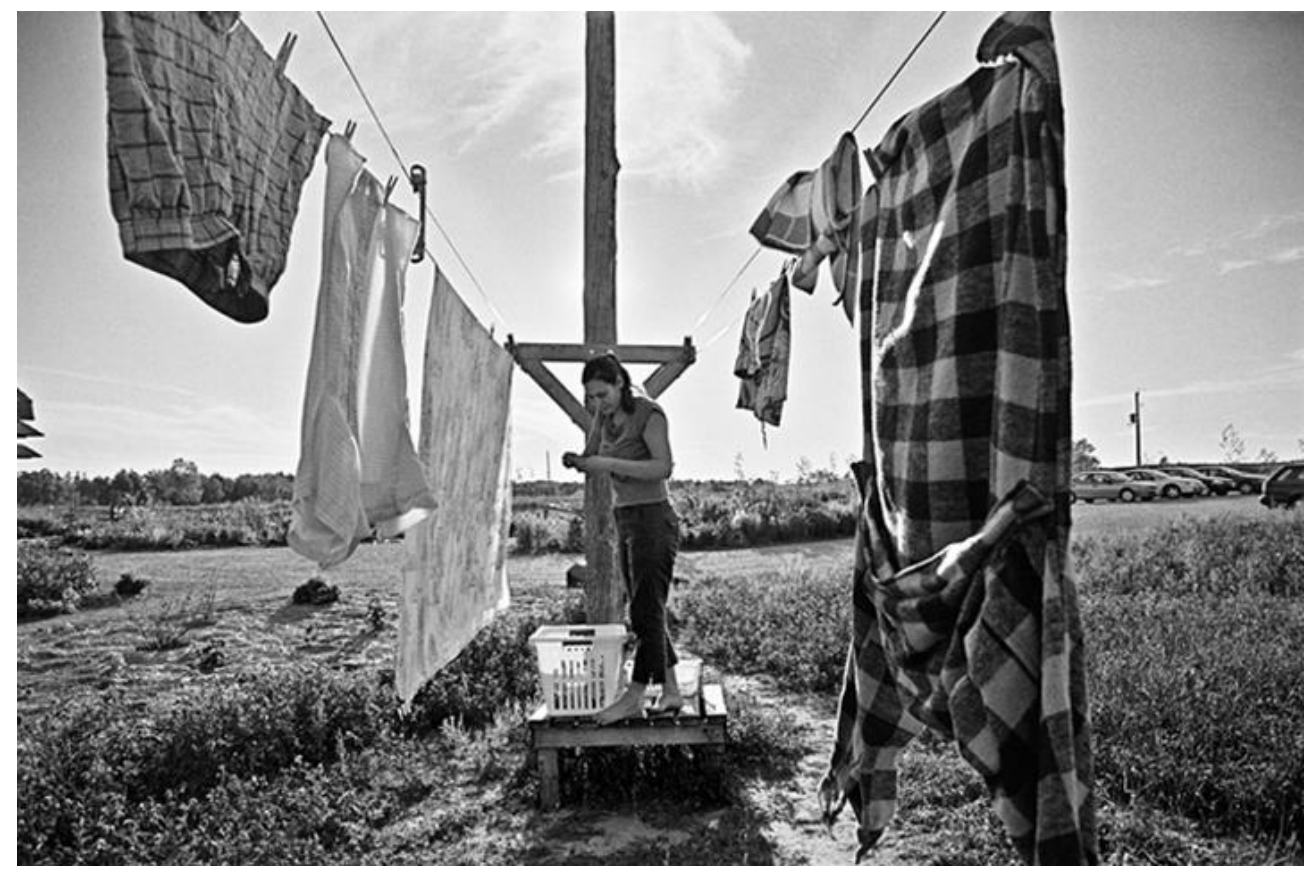

Steph, one of the community`s youngest members, hangs laundry to dry outside the Big Building.

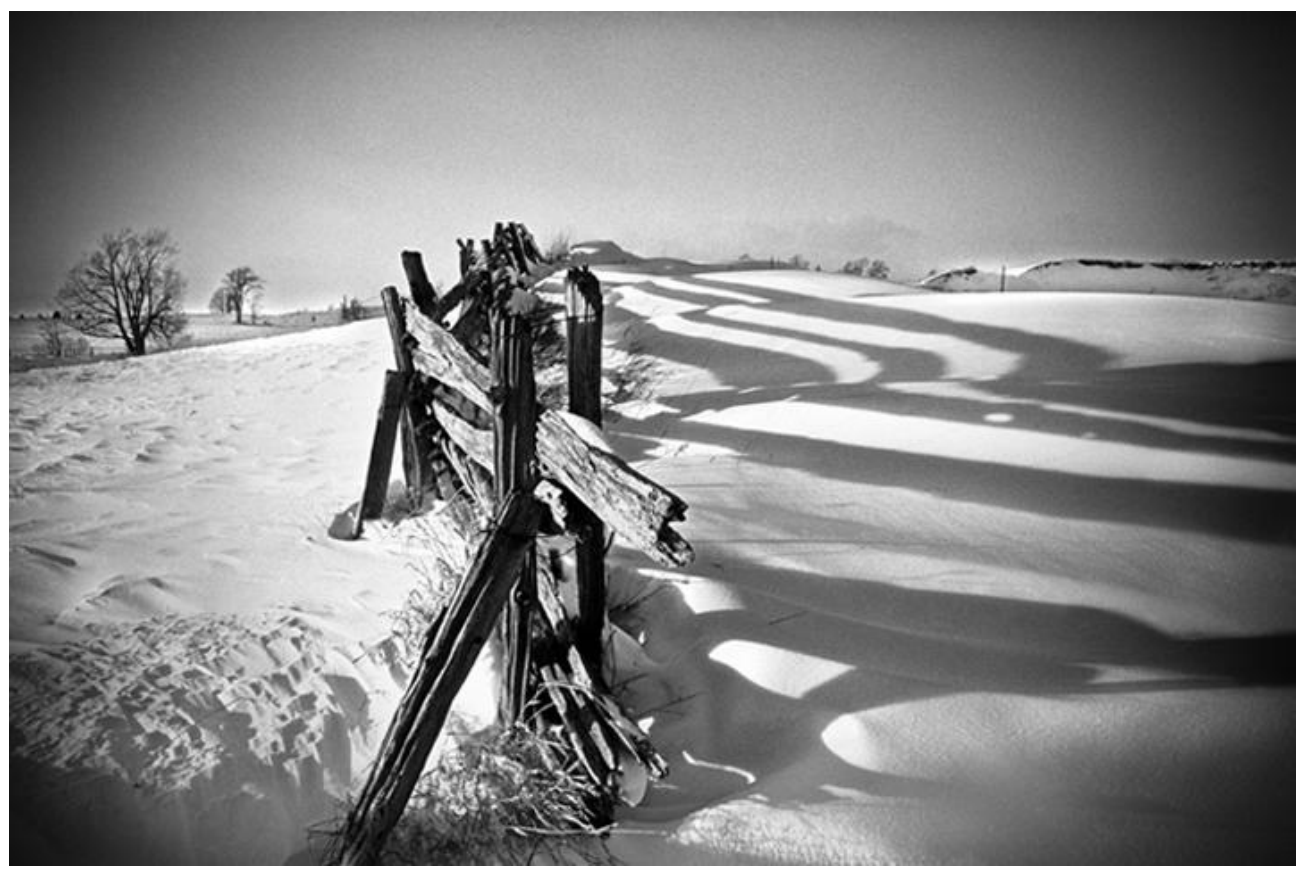

A fence casts shadows across a snow-covered field behind the barn.

ECJ Volume 2, No. 1, 2012 


\section{In the Big Building}

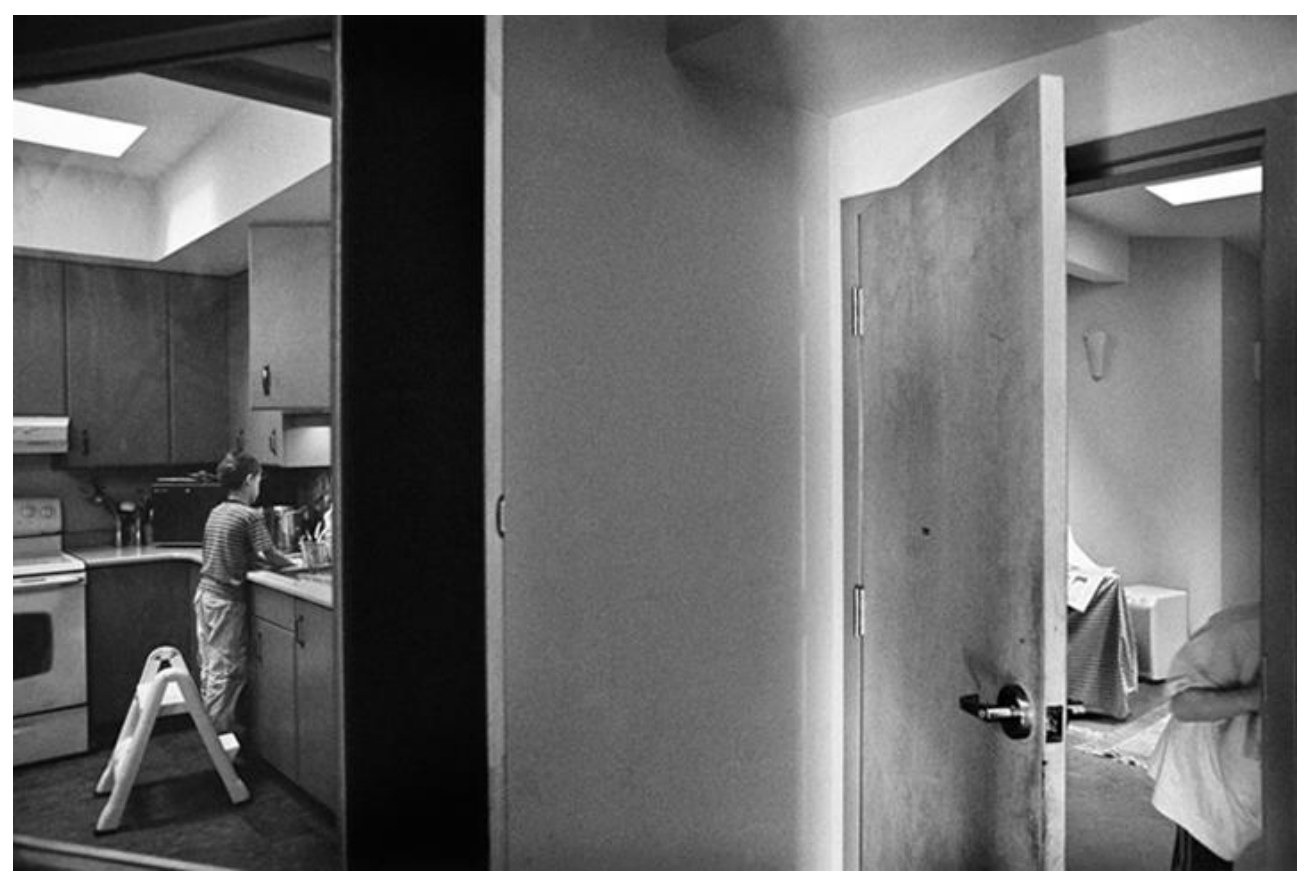

Erik does the dishes in his family`s suite in the Big Building while his elder brother plays in a neighbouring common area.

Doris collects me from the bus station on a dark winter evening, and on the way out of town we stop at the drugstore for cigarettes-her one vice, she explains, against the recent stresses of community life. Back at the farm there is minestrone and cornbread in the kitchen, saved from dinner for late arrivers like Doris and myself. I eat at the high counter while she brings me up to date on recent events, the corners of her eyes crinkling behind her school teacher's glasses as she tells me about sneaking the bulbs in before the frost, and about her new fruit tree. She is less optimistic about the roof: a fault in the water sealant has allowed ice to form above the ceiling, and on warmer days the corner of the common room has been weeping. Her chief concern, though, is the educational wellbeing of the community's few children, and she confides in me that the home schooling approach has been lacking lately:

"I'm in favour of home schooling, but as a teacher myself I find that the parents are usually fairly limited. If the whole community were involved it would be much broader: there would be a lot more interaction, as well as a blending of pedagogies. It will probably evolve 
if we get more young kids here. I know the Smiths (a visiting family) will want a broad education for Toby (age 3), if they decide to stay and home school, so the possibilities will open up. Right now, the way things are, there are a lot of elements missing from their education. There are some things the parents are not interested in, like the sciences, which is unfortunate because this place is perfect for that. I'd love to take that on, and I've taken them out from time to time to teach them some gardening, but to be honest I just don't have the time. And I feel guilty. Perhaps not guilty, but I feel bad for their education."

\section{In the Old Farmhouse}

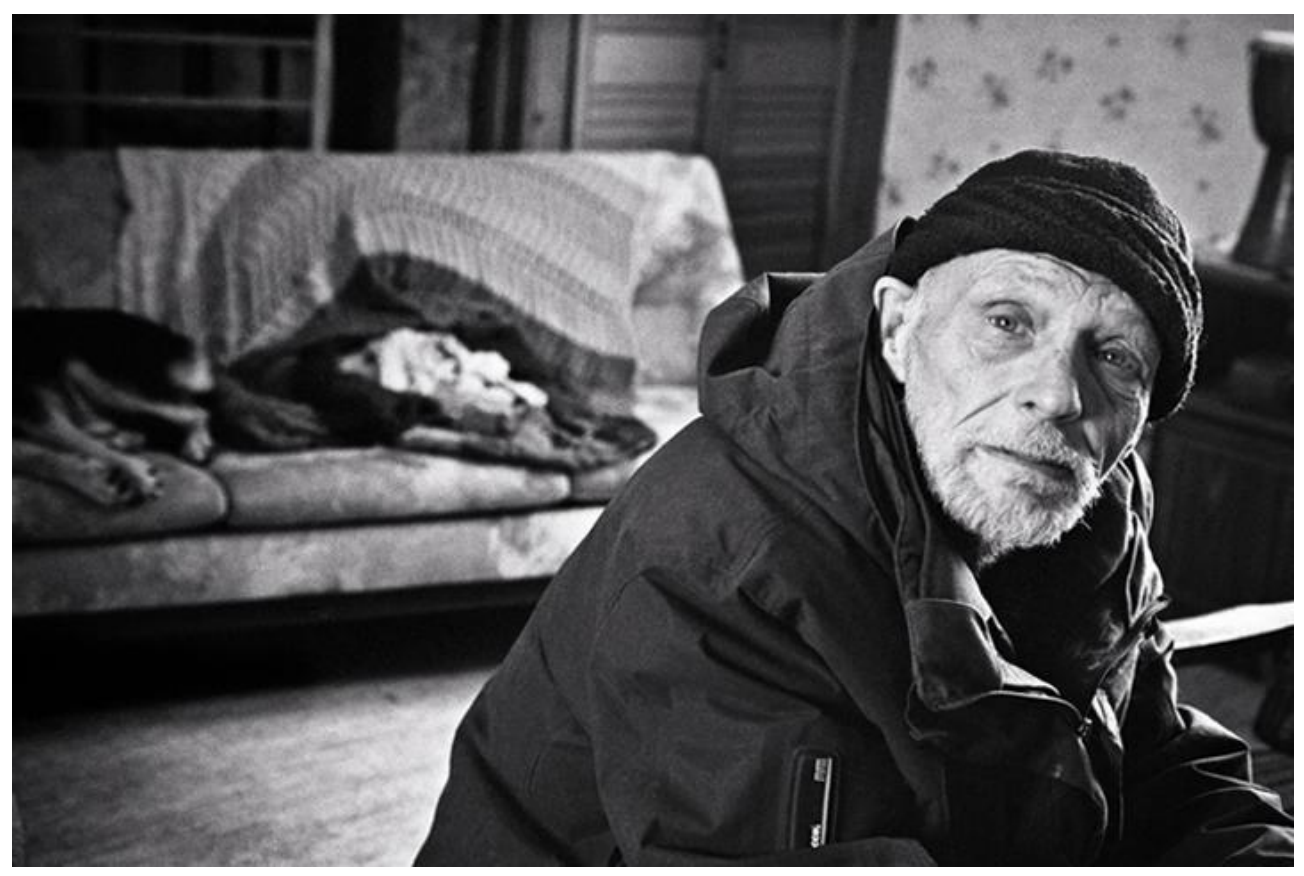

Steph`s father Rob, seen in front of the fire in the old farm house.

I visit Emery, Steph, and Thom in the farmhouse. The men are playing chess and churning butter simultaneously, the mason jar full of thick yellow cream passing back and forth, shaken by one as the other contemplates the next move. Emery has won seven games in a row, and the butter is nearing completion.

Steph and her husband Kenny have been trying to sell their suite in the Big Building for close to two years, they tell me as we sit in front of the fire. The only full 
community members under the age of forty, they bought into the farm with the help of Steph's aunt Marianne, one of the community's founding members, who agreed to cover the $\$ 50,000$ required by each new couple to retroactively contribute to the cost of the farmland. The $\$ 120,000$ for their suite quickly turned into $\$ 150,000$ as the construction process dragged on, and they became aware soon after moving in that community life was not for them. Steph sites the impact of the isolation on her relationships with her friends living off-property as a major factor, as well as the pressure of finding a balance between her job as a social worker in a nearby town and her duties on the farm, "which is also basically a full-time job." The problem they now face is that whoever buys their suite must first be approved by every other member of the community, and the task has been difficult. "I don't understand," Steph says in criticism of the consensus decision making process, "Wouldn't you rather share your space with someone who truly wants to be there, and wants to contribute, rather than with people who are resentful of not being able to leave?" Henrietta and Howie are renting their suite in the meantime, providing Steph and Kenny with an income that is only as stable as the visiting family.

\section{On the Pond}

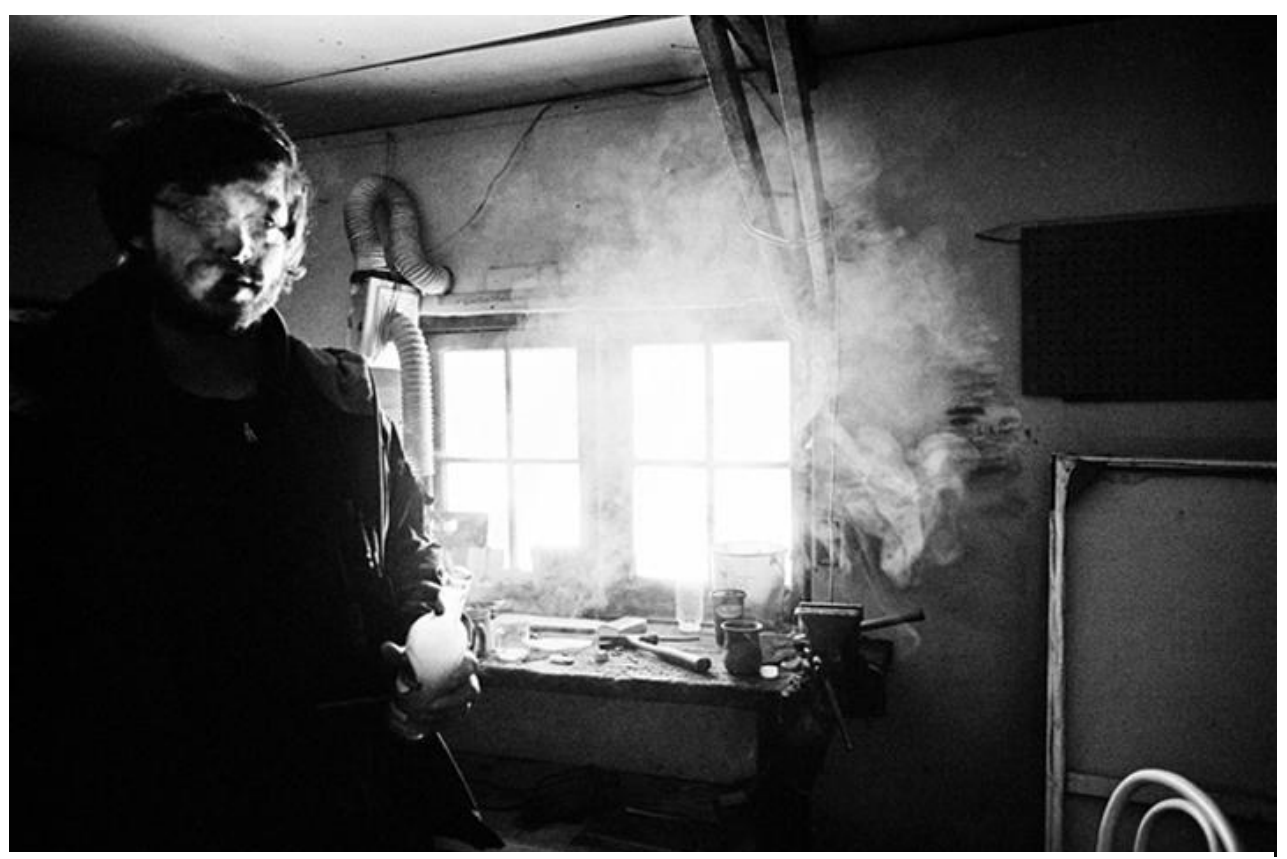

Thom smokes pot in a CSA storage shed before returning to work. 
Thom, a seasonal volunteer, smokes pot from a makeshift pipe in the back room of the work shed later in afternoon before finishing chopping wood for the fire. Timothy Smith smokes a cigarette outside, and Begbie the dog waits by the door, his head visible through the large hole that functions as a handle in the sliding door. The bench of the back room is covered with old tools that have most likely been forgotten by everyone but the farm's young volunteers, who use the screwdrivers to roll joints and 'pack bowls' in the diffuse light that pours in through the cluttered window overlooking the Community Shared Agriculture (CSA) shed.

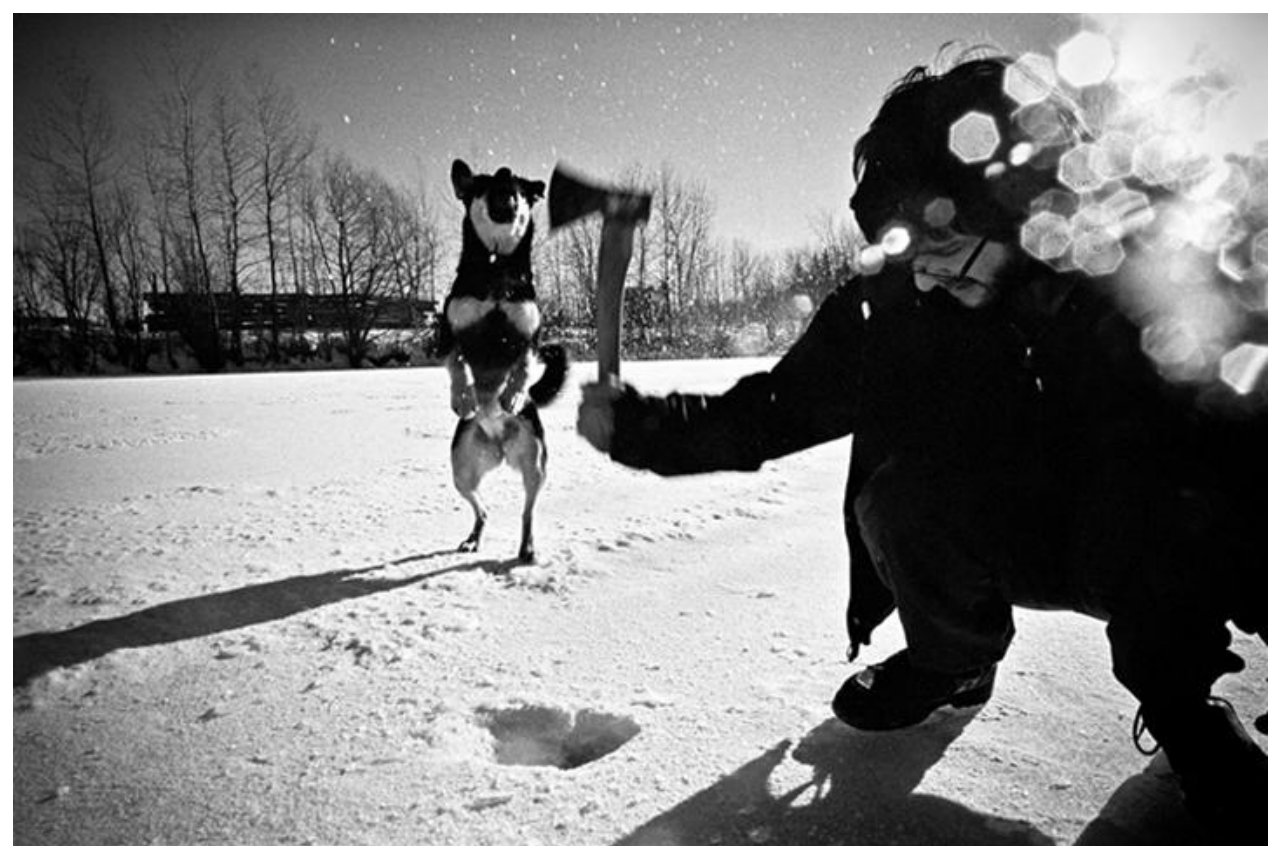

Thom tests the ice on the pond while Begbie jumps for flying ice chips;

Earlier that day Thom showed me how to test the thickness of ice on a body of water-something I, being from coastal British Columbia, had little experience with. Easing his way towards the center of the pond, hatchet in hand, he proceeded to hack small holes in the ice, testing the depth to the water below as he went while Begbie the dog leaped to catch flying ice chips in his mouth. Back on shore, Kaye's v-bottom canoe sat covered in snow, unused since the summer. 


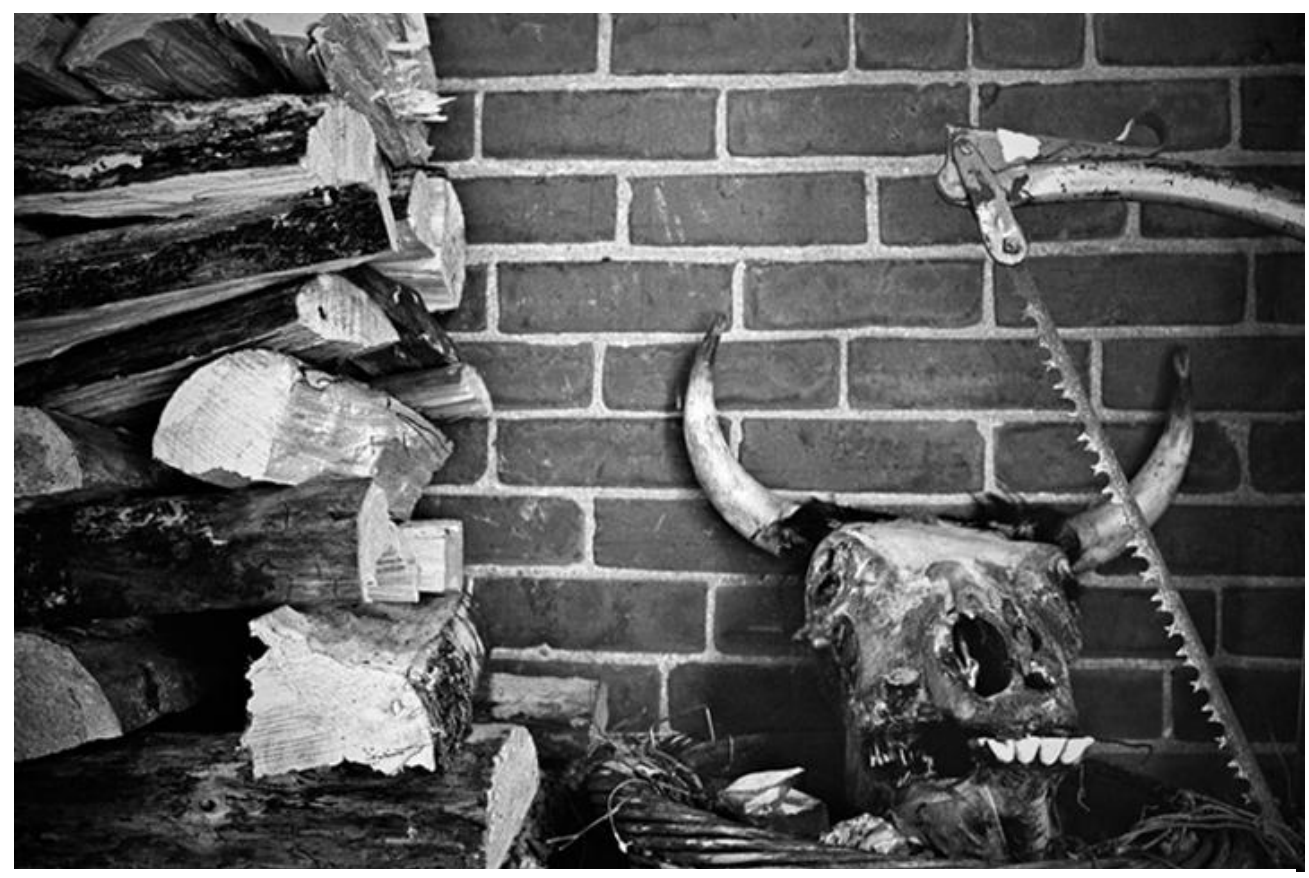

A cow skull sits in the wood shed of the old farm house.

\section{In the Driveway}

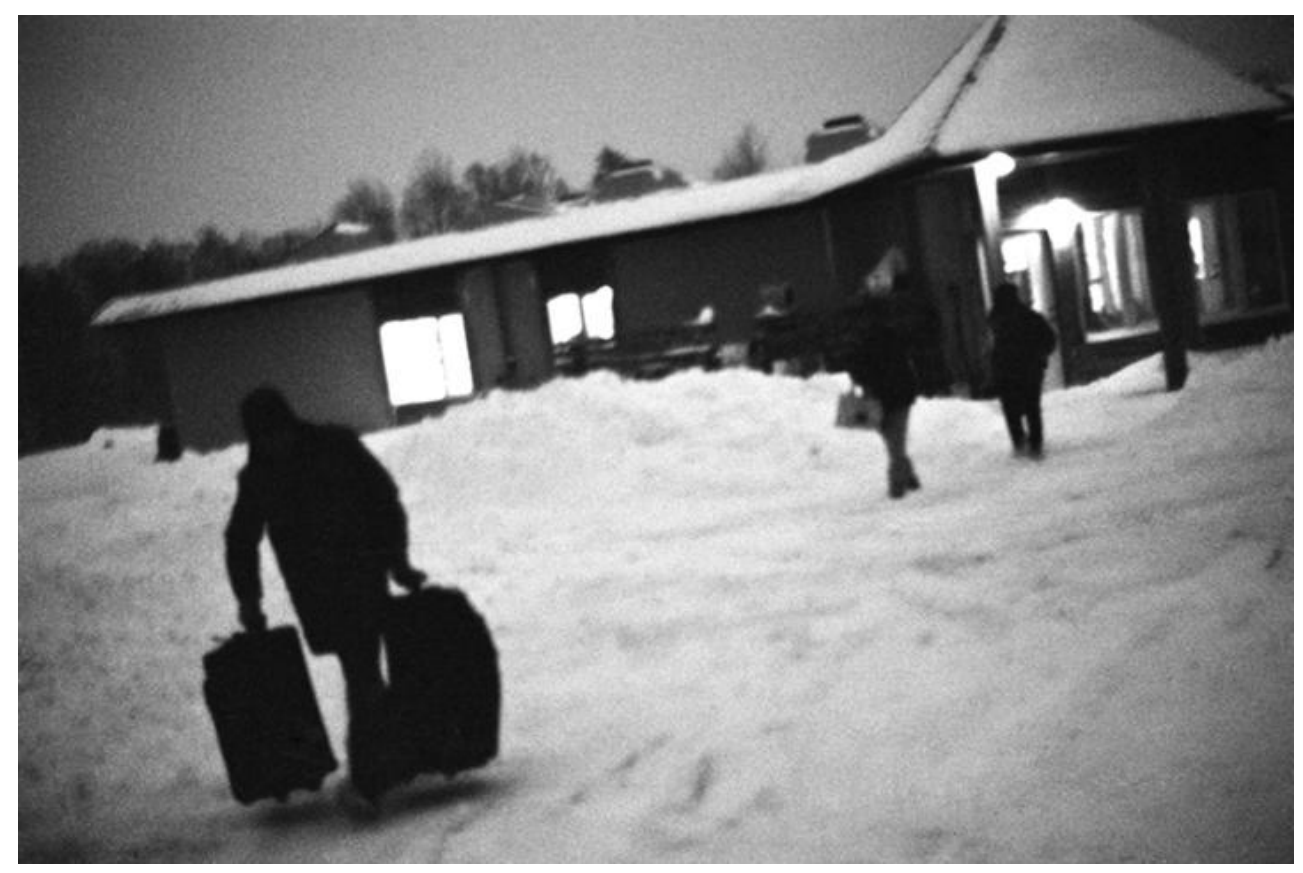

Kenny carries suitcases through the parking lot before leaving the community.

ECJ Volume 2, No. 1, 2012 
Ziv arrives in the late evening, his headlights appearing first as two eyes among the trees on the horizon, the car slowly sniffing its way home between the snow drifts that line the driveway. Alan is moving onto the farm in the next few days, and the bulk of his things fill the back of the car and part of the roof creating the impression of an old-time covered wagon. I help $\mathrm{Ziv}$ and Daniel carry the boxes through the snow to the rec room door. Later still, Steph's mom arrives to help her and Kenny pack. The two women are going on a short vacation in California before the couple moves to a small northern town, and at the last minute they convince Kenny to come with them. He agrees, eager for some respite from the icy air of the community, and carries the suitcases out to the car through the last of the snow.

\section{Conclusions}

The various practices of dwelling in an ecovillage may be familiar to most. Preparing food, playing with a child, washing dishes; like sawing a plank, these are tasks that are processional in their familiarity (Ingold, 2011, pp. 51-62). Other practiceslike sorting through blighted potatoes, milking a cow, spinning honey, making cheese, or walking the rafters of a barn-may be less familiar, but they are nonetheless integral to the incorporation of an ecovillage as a place. As tasks they are assembled along lines, be they lines of narrative and temporal sequence that through convention dictate the order of activities over the course of a day (Ingold, 2008, pp. 1796-1810), or physical lines such as the driveways and rows that lead us between buildings and barns and between tomatoes in fields. In their multimodal exploration of an island as a place, (Vannini \& Taggart, 2012, pp. 1-18) assert that "inhabitants incorporate a place by sheer practical, creative, skillful engagement with its affordances ... solving going concerns as they present themselves" (p. 3). The same can be said of the inhabitants of an ecovillage, as members make practical uses of the affordances of their environment and creatively solve the problems. In the ecovillage, however, familiar tasks are undertaken in unfamiliar ways, in a vast and varied social landscape. 


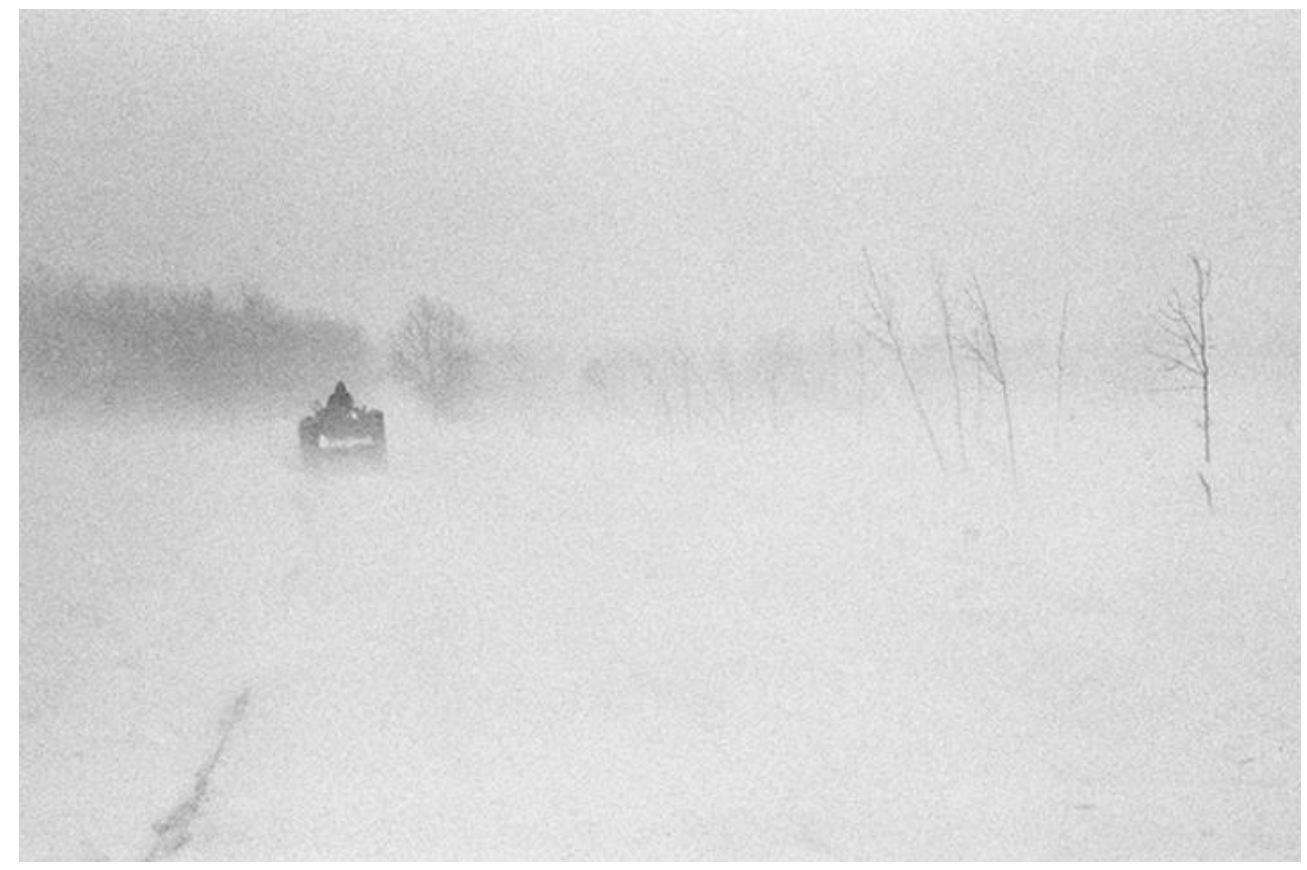

Community members work together to clear the parking lot of the Big Building after heavy snowfall.

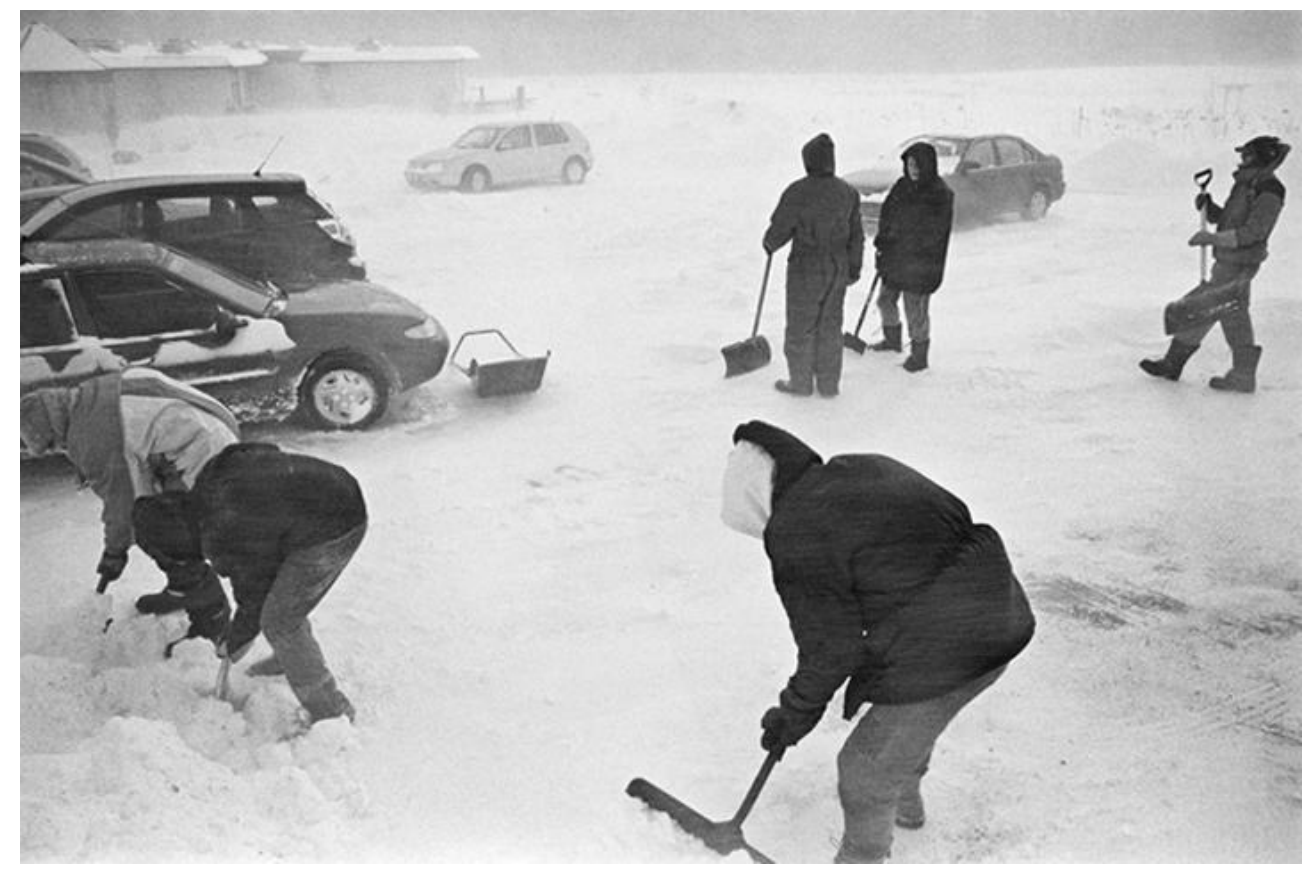

Community members work together to clear the parking lot of the Big Building after heavy snowfall.

ECJ Volume 2, No. 1, 2012 
*Writer: Jonathan Taggart is a Master of Arts student at Royal Roads University's School of Communication and Culture, as well as a professional documentary photographer and photojournalist. His current work blends visual narrative with elements of social inquiry and has as its central theme the movement of people through postcolonial space, towards isolated communities, and under remote economies.

\section{References}

Conn, S. (2010). Back to the garden: Communes, the environment, and antiurban pastoralism at the end of the sixties. Journal of Urban History, 36(6) 831-848.

Cassell, J. (1988). The relationship of Observer to Observed when Studying Up. Studies in Qualitative Methodology, 1, 89-108.

Crang, M., \& Cook, I. (2007). Doing ethnographies. London: Sage.

Cresswell, T. (2010). Towards a politics of mobility. Environment and Planning D: Society and Space, 28, 17-31.

Ellis, C. (2004). The ethnographic I: a methodological novel about autoethnography. Lanham, MD: AltaMira Press.

Ergas, C. (2010). A model of sustainable living: Collective identity in an urban ecovillage. Organization \& Environment 23(1), 32-54.

Fotopolous, T. (2000). The limitations of life-style strategies: the Ecovillage 'movement' is not the way towards a new democratic society. Democratic Society \& Nature, 6(2), 287-308.

Gaia Trust. (n.d.). What is an ecovillage? Retrieved from http://www.gaia.org/gaia/ecovillage/

Gibson, J.J. (1979). The ecological approach to visual perception. Boston: Houghton Mifflin.

Ingold, T. (2011). Being alive: essays on movement, knowledge and description. London: Routledge.

Ingold, T. (2005). The eye of the storm: visual perception and the weather. Visual Studies, 20(2), 97-104.

Ingold, T. (2008). Bindings against boundaries: entanglements of life in an open world. Environment and Planning A, 40, 1796-1810.

Kasper, D. V. S. (2008). Redefining community in the ecovillage. Ecology Review, 15(1), $12-24$.

Kilián, I. (2009). Ecovillages: In vitro sustainability. World Futures, 65, 365-371.

Lietaert, M. (2010). Cohousing's relevance to degrowth theories. Journal of Cleaner Production, 18, 576-580. 
Lorimer, H. (2005). Cultural geography: The busyness of being "more-thanrepresentational. Progress in Human Geography, 29(1), 83-94.

Miller, T. (1999). The 60s communes: Hippies and beyond. Syracuse, NY: Syracuse University Press.

Moustakas, C. (1994). Phenomenological research methods. Thousand Oaks: Sage. Sontag, S. (1973). On photography. New York, NY: Farrar, Straus and Giroux.

Pink, S. (2001). Doing visual ethnography. London: Sage.

Vannini, P., \& Taggart, J. (2012). Doing islandness: A non-representational approach to an island's sense of place. Cultural Geographies, 1-18.

Vannini, P. (2011). Constellations of ferry (im)mobility: islandness as the performance and politics of insulation and isolation. Cultural Geographies, 18(2), 249-271. 